\title{
COMUNICAÇÕES
}

\section{IMUNOPATOLOGIA DO BAÇO NA LEISHMANIOSE VISCERAL}

\author{
Edgar M. Carvalho, Argemiro D’Olivelra Junior e Aristides C. Quelroz
}

\begin{abstract}
Depressão da imunidade celular 28 e hiperglobulinemia ${ }^{8}$ são achados freqüentes na leishmaniose visceral. Numa tentativa de correlacionar os dados histológicos dos órgãos linfóides com as anormalidades imunológicas descritas nestes pacientes, foi procedido exame histopatológico do baço de 15 pacientes que faleceram com o diagnóstico de leishmaniose visceral, e estes dados foram comparados com os achados clínicos, laboratoriais e imunológicos.
\end{abstract}

O diagnóstico da leishmaniose visceral foi confirmado em todos os casos pela demonstração de leishmânia em material obtido da medula óssea. Estes 15 casos foram submetidos à autopsia completa com exame sistemático, macro e microscópico, de todos os órgãos, no Serviço de Anatomia Patológica do Hospital Professor Edgard Santos, em Salvador, Bahia. Os fragmentos do baço para exame histopatológico foram fixados em formol a $10 \%$, incluidos em parafina, seccionados com a espessura de 5 micrômetros e corados pelos métodos da hematoxilina e eosina. Os dados referentes ao peso do baço e à presença de doença associada foram obtidos dos protocolos de necropsia. Os prontuários clínicos foram também revistos com a finalidade de se obterem os dados referentes a idade, sexo, bem como achados clinicos e laboratoriais.

Em dois destes casos foi realizada determinação da população de linfócitos no sangue periférico. Para realização destes testes, células mononucleares foram obtidas de sangue heparinizado por meio de centrifugação por gradiente de densidade usando meio de separação de linfócitos (Bionetics Laboratories). Após lavagem e depleção dos macrófagos, através da capacidade de aderência destas células à superfície plástica, foi feita determinação de linfócitos $T$ e de linfócitos $B$, respectivamente, pela capacidade de ligação a hemácias de carneiro e por detecção de

Laboratório de Imunologia e Serviço de Anatomia Patológica do Hospital Professor Edgard Santos - UFBa. imunoglobulina de membrana através da imunofluorescência indireta, por técnicas já previamente descritas 610 .

Os principais achados clínicos e o estudo histopatológico do baço são mostrados na Tabela 1. Dez dos 15 pacientes eram do sexo masculino, e a idade variou de 2 a 30 anos com mediana de 9 . A duração da doença variou de 1 a 18 meses (média e desvio-padrão $=9 \pm 4,7$ ). Todos os pacientes apresentavam anemia e leucopenia quando da internação, e a albumina sérica estava abaixo de $2,5 \mathrm{~g} / \mathrm{dl} \mathrm{em} 14$ dos 15 casos. A globulina sérica estava aumentada em todos os casos, tendo variado de 3,8 a $9 \mathrm{~g} / \mathrm{dl}$ (média e desvio-padrão $=6$ $\pm 1,6$ ). Aumento do tamanho e do peso do baço foi observado em todos os casos. A avaliação histopatológica revelou atrofia dos folículos linfóides em 10 casos, com acentuada redução dos centros germinativos, que às vezes estavam ausentes. Contrastando com estes achados, constatou-se hiperplasia dos foliculos linfóides em 4 casos, enquanto que em um caso estas estruturas estavam dentro dos limites normais. Redução do número de linfócitos nas áreas periarteriolares foi achado constante e mais significativo no presente estudo, sendo observado em 14 dos 15 baços estudados. Os componentes celulares da polpa vermelha do baço estavam representados por plasmócitos e células fagociticas. Focos de plasmocitose foram observados em todos os casos. Nas células fagociticas tanto pode ser observada a presença de material hialino intracelular como, em alguns casos, a presença de eritrócitos fagocitados.

Com a finalidade de avaliar se poderia haver uma associação entre o aspecto do folículo linfóide e a idade dos pacientes, duração da doença e niveis de globulina sérica, os 15 casos foram divididos em dois subgrupos, sendo um constituido pelos 10 casos que apresentavam folículos linfóides atróficos e outro constituido de 5 casos nos quais os folículos linfóides eram hiperplásicos ou normais. No grupo com foliculos atróficos a mediana da idade foi 10 , a média e desvio-padrão da duração da doença foi 10 meses \pm

Recebido para publicaçăo em 6/9/84. 
Tabela 1 - Correlação entre duração da doença, globulina sérica e aspectos histopatológicos do baço em portadores de leishmaniose visceral.

\begin{tabular}{|c|c|c|c|c|c|c|}
\hline Idade/Sexo & $\begin{array}{c}\text { Duração } \\
\text { da } \\
\text { doença }\end{array}$ & $\begin{array}{l}\text { Globulina } \\
\quad g / d l\end{array}$ & $\begin{array}{l}\text { Aspecto do } \\
\text { folículo } \\
\text { linfóide }\end{array}$ & $\begin{array}{l}\text { Redução de } \\
\text { linfócitos } \\
\text { periarteriolares }\end{array}$ & Plasmocitose & Fagocitose \\
\hline $4 / M$ & 1 & 5,4 & normal & +++ & +++ & +++ \\
\hline $5 / F$ & 2 & 3,8 & hiperplásico & ausente & ++ & ++ \\
\hline $4 / F$ & 3 & 7,1 & atrófico & +++ & +++ & +++ \\
\hline $30 / \mathrm{M}$ & 6 & 8,0 & atrófico & + & ++ & ++ \\
\hline $24 / M$ & 6 & 9,5 & hiperplásico & +++ & $++t$ & +++ \\
\hline $19 / \mathrm{M}$ & 7 & 7,0 & atrófico & ++ & +++ & +++ \\
\hline $10 / \mathrm{M}$ & 7 & 6,5 & atrófico & ++ & ++ & ++ \\
\hline $18 / \mathrm{M}$ & 8 & 3,8 & atrófico & +++ & +++ & +++ \\
\hline $3 / F$ & 12 & 5,3 & hiperplásico & ++ & +++ & +++ \\
\hline $2 / F$ & 12 & 5,5 & hiperplásico & ++ & + & - \\
\hline $10 / \mathrm{M}$ & 12 & 6,0 & atrófico & +++ & +++ & +++ \\
\hline $5 / F$ & 12 & 5,2 & atrófico & +++ & +++ & - \\
\hline $22 / \mathrm{M}$ & 12 & 8,3 & atrófico & +++ & +++ & +++ \\
\hline $9 / \mathrm{F}$ & 12 & 7,1 & atrófico & +++ & + & + \\
\hline $8 / \mathbf{M}$ & 18 & 4,6 & atrófico & ++ & +++ & +++ \\
\hline
\end{tabular}

4,3, e a média das globulinas séricas foi $6 \mathrm{~g} / \mathrm{dl} \pm 1,4$. No grupo com folículo normal ou hiperplásico a mediana de idade foi 4 , a média de duração da doença foi 7 meses $\pm 5,3$, e a média das globulinas séricas foi 6 $\mathrm{g} / \mathrm{dl} \pm 2,1$. Em dois casos (nos 1 e 8 ) marcadores de superficie foram utilizados para quantificar os linfócitos T e linfócitos B. Em um caso (n. 4) o percentual de linfócitos $\mathrm{T}$ foi de $75 \%$ com valor absoluto de 1231 células por $\mathrm{mm}^{3}$ e o percentual de linfócitos $\mathrm{B}, 7 \%$ com valor absoluto de 133 células por $\mathrm{mm}^{3}$. No caso n. 7 o percentual de linfócitos $T$ foi de $50 \%$ (620 células $/ \mathrm{mm}^{3}$ ) e o de linfócitos $\mathrm{B}, 6 \%$ (297 células $/ \mathrm{mm}^{3}$ ). Comparando estes resultados com os valores obtidos de controles normais em nosso laborató$\mathrm{rio}^{4}$, pode ser visto que, enquanto em um paciente o percentual de linfócitos $T$ estava dentro dos limites normais, no outro era inferior à média menos dois desvios-padrão, comparado ao de indivíduos sadios. Em ambos os pacientes foi documentada depleção de linfócitos em áreas periarteriolares.

Depleçăo linfocitária em áreas $\mathrm{T}$ dependentes foi um achado observado na quase totalidade dos casos de leishmaniose visceral no presente estudo. Esta observação confirma os achados prévios de Veres et al. ${ }^{9}$, em pacientes - com leishmaniose visceral - na Índia. Todavia, enquanto em 15 dos 20 casos estudados por Veres et a $l^{9}$ o periodo de duração da doença era longo, o estado nutricional era precário e o diagnóstico de leishmaniose visceral só foi documentado no estudo post mortem, no presente trabalho a depleção de linfócitos em áreas periarteriolares foi documentada mesmo nos casos nos quais a doença tinha um curto período de evolução. Depleção linfocitárìa em áreas $\mathrm{T}$ dependentes são documentadas em animais timectomizados após o nascimento ${ }^{7} \mathrm{e}$ após a administração de soro antilinfócitos 1 . Ambas as possibilidades não se aplicam ao que ocorre na leishmaniose visceral. Anormalidades do timo não têm sido descritas nesta protozoose e desde que a restauração da resposta imunitária celular ocorre após terapêutica da leishmaniose visceral ${ }^{2}$ é improvável que um defeito no timo seja a causa da ocorrência da depleção linfocitária. A documentação, por outro lado, de que o soro de pacientes com leishmaniose visceral não inibe a formação de rosetas de linfócitos $\mathrm{T}^{2}$ e de que anticorpos antilinfocitários não estão presentes em pacientes com leishmaniose visceral (observação pessoal) não apóiam a idéia de que anticorpos antilinfócitos sejam relacionados com a depleção linfocitária nas áreas periarteriolares. Como a leishmaniose visceral é uma doença na qual o agente infectante persiste no hospedeiro por um longo periodo de tempo, é possivel que a estimulação constante de linfócitos, mediada pelos vários antigenos de parasito, termine por induzir uma tolerância imunológica e, por conse- 
Carvalho EM, D'Oliveira Jr. A, Queiroz AC. Imunopatologia do baço na leishmaniose visceral. Revista da Sociedade Brasileira de Medicina Tropical 18: 109-112, Abr-Jun, 1985

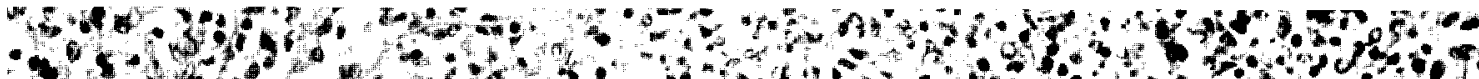



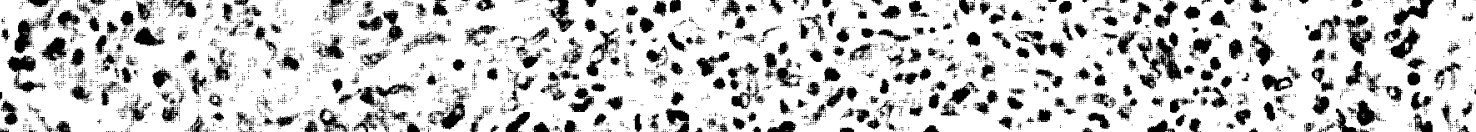



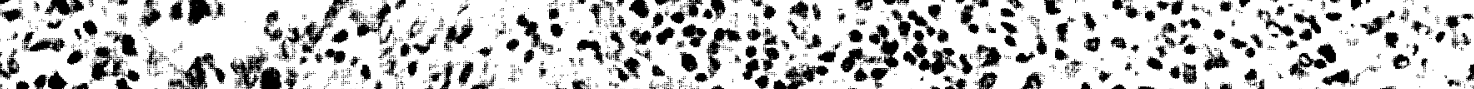

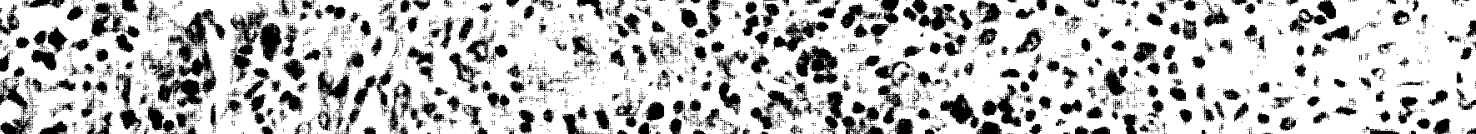
$2+42 n$.

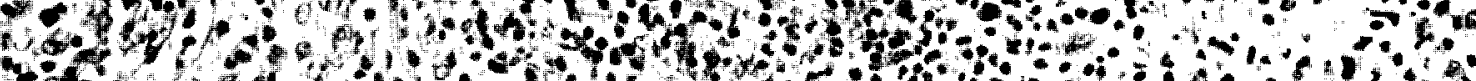

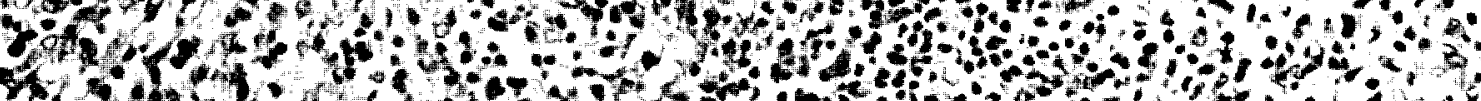

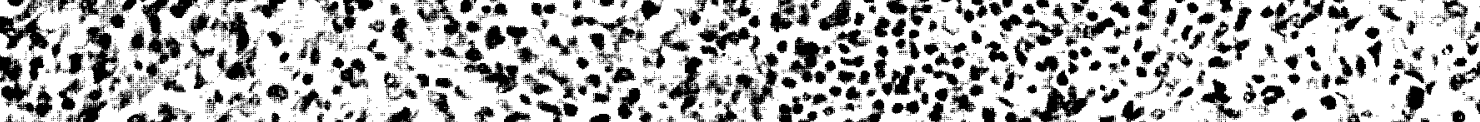

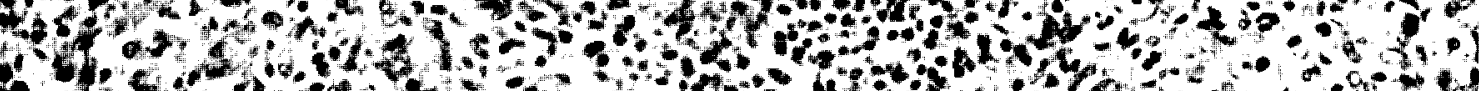



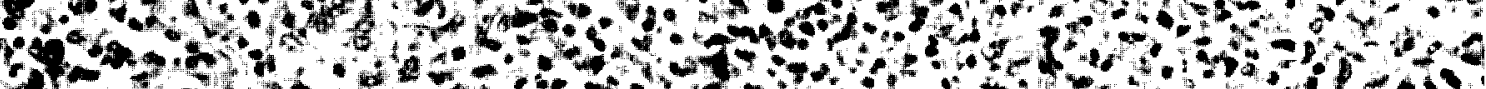

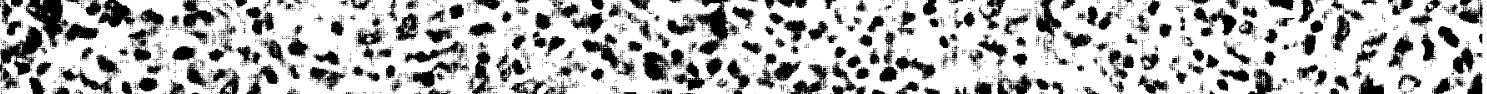

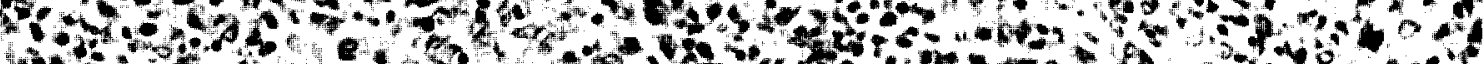
Het.

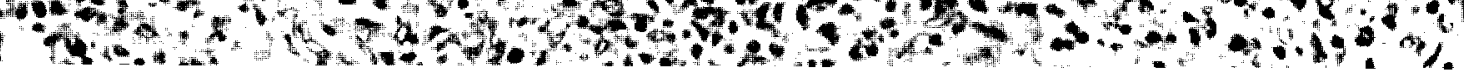

Fig. 1 - Corte de baço mostrando acentuada atrofia de folículo linfóide. Hematoxilina e eosina. x 200.



Fig. 2 - Acentuada redução de linfócitos da região periarteriolar na parênquima esplênico. Hematoxilina e eosina. x 400. 
guinte, uma diminuição de linfócitos em áreas $\mathbf{T}$ dependentes. Alternativamente, a diminuição de linfócitos poderia estar relacionada com a desnutrição ${ }^{5}$, ou com a presença de substâncias séricas que suprimem a proliferação linfocitária ${ }^{3}$.

Os achados histológicos do baço na leishmaniose visceral são compativeis com as diversas anormalidades da imunidade celular observadas nestes pacientes. $O$ fato de que, tanto no paciente que tinha linfócitos $\mathrm{T}$ diminuidos no sangue periférico como no paciente que tinha preservado o número de linfócitos $\mathrm{T}$, havia depleção de linfócitos em áreas $\mathrm{T}$ dependentes do baço, sugere que as anormalidades neste órgão precedem ou são mais evidentes do que as observadas no sangue.

$\mathrm{O}$ aspecto dos folículos linfóides, áreas onde predominam os linfócitos B, situou-se em dois extremos: tanto sendo observada atrofia como hiperplasia folicular. A possibilidade de que em uma fase inicial da leishmaniose visceral houvesse hiperplasia dos foliculos linfóides e que com o decorrer da doença surgisse atrofia é viável, desde que em 3 dos 5 casos nos quais o folículo linfóide estava normal ou hiperplasiado, a duração da doença foi igual ou inferior a 6 meses, enquanto que somente em 2 dos 10 casos nos quais a atrofia foi documentada o periodo de doença foi inferior a 6 meses.

Hiperglobulinemia foi documentada em todos os casos e não houve associação entre os niveis de globulina e o aspecto do folículo linfóide. Todavia, hiperglobulinemia correlacionou-se bem com a intensa plasmocitose observada no baço destes pacientes. É importante que, a despeito da plasmocitose no baço, os linfócitos B no sangue periférico de 2 pacientes com leishmaniose visceral estavam em niveis normais. Esta dissociação entre o que ocorre em um órgão linfóide e o sangue periférico é um dado importante, desde que as células sangüineas são as utilizadas para a avaliação imunológica na espécie humana. Neste caso, o estudo da imunidade poderia nem sempre refletir o que ocorre nos órgãos linfóides ou nos locais onde o agente infectante é abundante, como é o caso da leishmânia no baço.

\section{REFERÊNCIAS BIBLIOGRÁFICAS}

1. Bryceson ADM \& Turk JL. The effect of prolonged treatment with antilymphocyte serum on the course of infection with BCG and Leishmania enrietti in the guinea-pig. Journal of Pathology 104: 153-165, 1971.

2. Carvalho EM, Teixeira R, Johnson WD Jr. Cell mediated immunity in American Visceral Leishmaniasis. Reversible immune suppression during acute infection. Infection and Immunity 22: 649-656, 1981.

3. Carvalho EM \& Bacellar O. Lymphocyte reactivity to mitogens in American Visceral Leishmaniasis. Brazilian Journal of Medical and Biological Research 16: 35-41, 1983.

4. Carvalho EM \& Bacellar O. Quantificação das populações de linfócitos em sangue periférico humano: Reconsideração a respeito das técnicas utilizadas. Revista Médica da Bahia 27: 9-12, 1983.

5. Keusch GT, Wilson CS, Waksal SD. Nutrition, host defenses and the lymphoid system. Advances in Host Defense Mechanisms 2:275-359, 1983.

6. Lobo PT. \& Horwitz DA. An appraisal of Fc receptors on human peripheral blood $\mathrm{B}$ and $\mathrm{T}$ lymphocytes. Journal of Immunology 117: 939-943, 1974.

7. Metcalf $\mathrm{D}$. The effect of thymectomy on the lymphoid tissue of the mouse. British Journal of Haematology 6: $324,1970$.

8. Rezai HR, Ardehali SM, Amirhakimi G \& Kharazmi, A. Immunological features of kala-azar. American Journal of Tropical Medicine and Hygiene 27: 1079$1083,1978$.

9. Veres B, Omer A, Satir AA \& Al Hassan AM. Morphology of the spleen and lymphnodes in fatal visceral leishmaniasis. Immunology 33:605-610, 1977.

10. WHO-IARC Workshop. Special technical report. Identification, enumeration and isolation of $\mathbf{B}$ and $\mathrm{T}$ lymphocytes from human peripheral blood. Scandinavian Journal of Immunology 3: 521-532, 1974. 